\title{
Preparation of symmetric bis-sulfides via reductive thiolation of dicarbonyl with thiols or of carbonyl compounds with dithiols in the presence of triethylsilane and boron trifluoride monohydrate ${ }^{1}$
}

\author{
Qi Wang, Xing-ya Li, G. K. Surya Prakash,* and George A. Olah*, \\ Donald $P$. and Katherine B. Loker \\ Hydrocarbon Research Institute and Department of Chemistry, \\ University of Southern California, Los Angeles, California 90089-1661, \\ U.S.A. \\ E-mail:gprakash@usc.edu
}

\section{Dedicated to Professor T. R. Govindachari on the occasion of his eighty-fifth birthday}

(received 02 May 01; accepted 30 Sep 01; published on the web 08 Oct 01)

\begin{abstract}
Symmetric organic bis-sulfides were prepared via reductive thiolation of dicarbonyl compounds with thiols or of carbonyl compounds with dithiols in the presence of triethylsilane and boron trifluoride monohydrate.
\end{abstract}

Keywords: Thiols and dithiols, carbonyl and dicarbonyl compounds, triethylsilane, boron trifluoride monohydrate, symmetric bis-sulfides

\section{Introduction}

Organic bis-sulfides are generally synthesized by the nucleophilic substitution of alkyl halides with thiolates. ${ }^{2}$ This procedure can be carried out by reacting either dithiols with monohalides or dihalides with monothiols. Other methods of preparation of bis-sulfides have also appeared sporadically in the literature. They usually deal with some 
specific types of bis-sulfides. For example, 1-n-butylthio-2-(1,1diaryalkylthio)ethanes and -propanes can be obtained by treating corresponding 2,2-diaryl-1,3-dithiolanes and -1,3-dithianes with $n$ butyl lithium followed by addition of alkyl halides. ${ }^{3 a}$ Vicinal bissulfides were prepared by either BF3 catalyzed addition of disulfides to alkenes or radical addition of two molar equivalents of thiol to acetylenes. $^{3 \mathrm{~b}, \mathrm{c}}$

We have earlier reported boron trifluoride monohydrate catalyzed one flask preparation of sulfides from carbonyl compounds with thiols and triethylsilane (eqn. 1). ${ }^{4}$
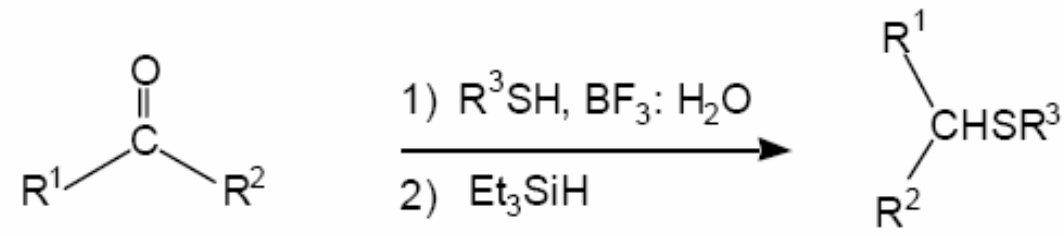

$$
\begin{aligned}
& 1 \\
& \mathrm{R}^{1}, \mathrm{R}^{3}=\text { alkyl, aryl; } \quad \mathrm{R}^{2}=\text { alkyl, } \mathrm{H}
\end{aligned}
$$

2

Kikugawa reported a similar transformation by using pyridineborane complex in trifluoroacetic acid medium. ${ }^{5}$ Our method ${ }^{4}$ is more general and works well with aliphatic ketones. No hydrogen gas is generated as in the case with Kikugawa's procedure. A comprehensive review on silicon mediated synthesis of sulfur containing molecules has appeared. ${ }^{6}$ We would like to report now the extension of our earlier method $^{4}$ for the preparation of organic bis-sulfides.

\section{Results and Discussion}

Aromatic dicarbonyl compounds react readily with two molar equivalents of thiol in the presence of triethylsilane and boron trifluoride monohydrate to give the corresponding bis-sulfides. ${ }^{7}$ When terephthaldicarboxaldehyde was reacted with ethanethiol and 1- 
propanethiol, $\alpha, \alpha^{\prime}$-bis(alkylthio)-p-xylenes were obtained in excellent yields (See Table 1), eqn. 2.

However, with 2-methyl-2-propanethiol and thiophenol, slow addition of the silane and proper amount of solvent were necessary to ensure formation of the bis-sulfides in good yield. Otherwise, precipitation occurred and lower yields of products ensued. Reaction of 1,4-diacetylbenzene with ethanethiol proceeded well to produce $\alpha, \alpha^{\prime}$ bis(ethylthio)-p-diethylbenzene (eqn. 3). 
Table 1. Continued

Monofuntional
Compound
Compound

a. $\mathrm{c}-\mathrm{C}_{6} \mathrm{H}_{11}=$ Cyclohexyl. 


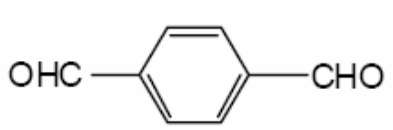

3
1) $\underset{\mathrm{RSH}, \mathrm{BF}_{3}: \mathrm{H}_{2} \mathrm{O}}{\mathrm{Et}} \mathrm{SiH}$

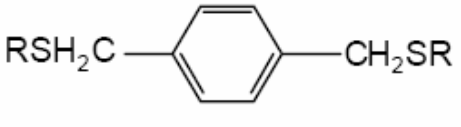

$4(a-e)$

$\mathrm{a}, \mathrm{R}=\mathrm{Et} ; \mathrm{b}, \mathrm{R} n-\mathrm{Pr} ; \mathrm{c}, \mathrm{R}=i-\mathrm{Pr} ; \mathrm{d}, \mathrm{R}=t-\mathrm{Bu} ; \mathrm{e}, \mathrm{R}=\mathrm{Ph}$.

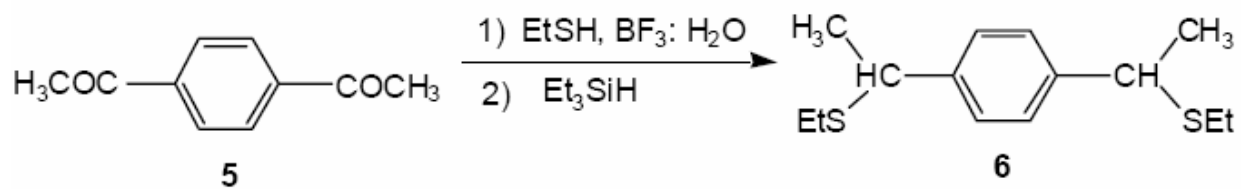

Thiolation of aliphatic dicarbonyl compounds was also studied. When 1,4-cyclohexandione was treated with ethanethiol and 2propanethiol, two stereo isomers, equatorial-equatorial and equatorialaxial, were obtained in a 1.3:1 ratio in both cases (by GC analysis), eqn.4. 1,4-Cyclohexandione was also reacted with 2-methyl-2propanethiol, with the expectation of changing the isomer ratio by increasing the bulkiness of the alkyl group of the thiol. The reaction, however, led to complex mixtures of products. This is in contrast to what was earlier observed in the monothiolation of carbonyl compounds with 2-methyl-2-propanethiol. In those cases, desired sulfides were obtained in good yields. ${ }^{4}$ However, it is difficult to rationalize these contrasting results.
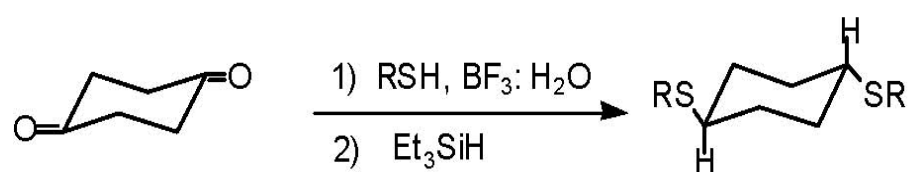<smiles>[R5]C1CCC([R5])CC1</smiles>

7

8(a-b)

a, $\mathrm{R}=\mathrm{Et} ; \mathrm{b}, \mathrm{R}=i-\mathrm{Pr}$ 
Reaction of 1,3-pentandione with thiols gives two diastereomers in each case. The isomer ratios (anti over syn or vice versa) for 1,3bis(ethylthio)pentane and 1,3-bis(i-propylthio)pentane, determined by GC analysis are 1.4 and 1.3, respectively (eqn. 5).

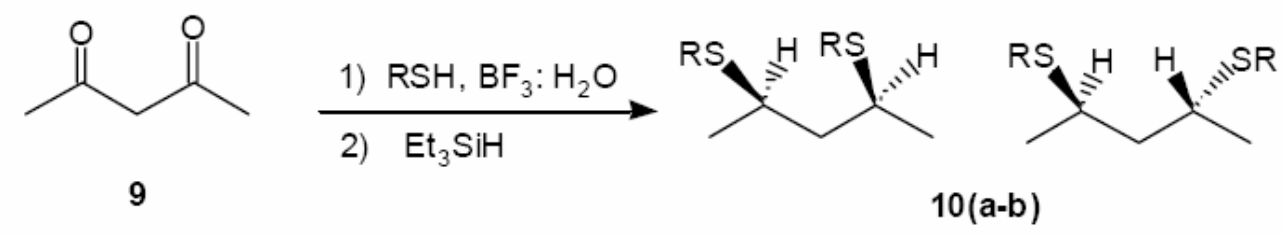

a, $\mathrm{R}=\mathrm{Et} ; \quad \mathrm{b}, \mathrm{R}=i-\mathrm{Pr}$.

When benzil and 1,2-butandione were used as substrates, desired vicinal bis-sulfides were obtained along with a series of other products. These by-products were, however, not separated and identified.

Another route to bis-sulfides that was explored was the reaction of dithiols with monocarbonyl compounds (eqn. 6). Aliphatic dithiols, wherein the thiol groups are separated by at least four methylene units, react with ketones cleanly to provide the expected bis-sulfides. Otherwise significant amount of cyclization products (i.e. thioacetals), derived from reaction of dithiols with one carbonyl group, are obtained.

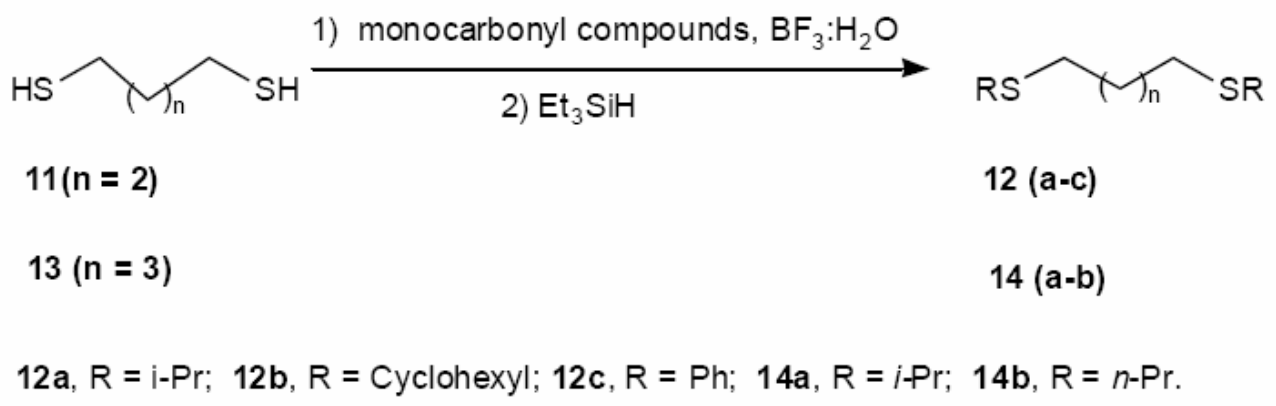

In case of aliphatic aldehydes, the needed separation is five methylene units. Besides cyclization, thiolation of aliphatic aldehydes 
is known to be affected by condensation of alkenyl sulfides ${ }^{4}$ generated in situ by dehydration of hemithioactals. ${ }^{8}$ We have encountered similar difficulties in the preparation of monosulfides. ${ }^{4}$ Lower boron trifluoride content hydrates 9 such as $\mathrm{BF} 3: 1.25 \mathrm{H}_{2} \mathrm{O}, \mathrm{BF}_{3}: 1.45 \mathrm{H}_{2} \mathrm{O}$, and $\mathrm{BF}_{3}: 2 \mathrm{H}_{2} \mathrm{O}$ were also investigated for the reaction, in hope of lessening the degree of condensation by reducing the acidity of the catalyst systems. However, the reactions proceed more sluggishly with increasing water content in the catalysts with no significant improvement in the yield of the desired products. Inverse addition of acids to mixture of dithiols and propionaldehyde led to partial reduction of the aldehyde.

Commercially available 1,3-benzenedithiol was also reacted as a representative aromatic dithiol. Good yield of $m$-(i-propylthio)benzene was obtained in the reaction with acetone. Lower yield of bis-sulfide was obtained in the reaction of 1,3-benzenedithiol with $n$-propionaldehyde (eqn.7).

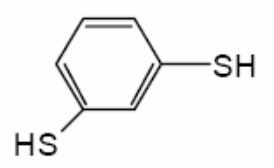

15

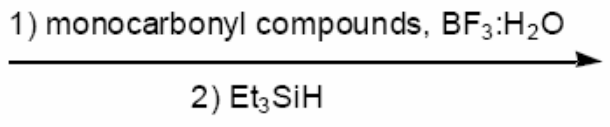

2) $\mathrm{Et}_{3} \mathrm{SiH}$

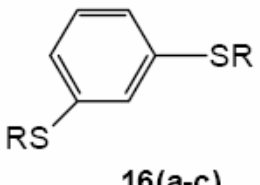

$16(a-c)$

a, $\mathrm{R}=n-\mathrm{Pr} ; \mathrm{b}, \mathrm{R}=i-\mathrm{Pr} ; \mathrm{c}, \mathrm{R}=\mathrm{Ph}$.

One flask preparation of unsymmetrical bis-sufides by described method was also attempted by sequential addition of two different thiols to terephthaldicarboxaldehyde. Along with the desired unsymmetrical bis-sulfides, some symmetric ones were also obtained. We further found that when terephthaldicarboxaldehyde reacted with only one molar equivalent of a single thiol, bis-sulfide was among the products.

In conclusion, we have found that reductive thiolation of carbonyl compounds is a general method for preparation of symmetric bissulfides. 


\section{Experimental Section}

General Procedures. All carbonyl compounds and thiols used were purchased from Aldrich, and used without further purification. Boron trifluoride was from Matheson Gas Products. Boron trifluoride hydrates were prepared according to a reported procedure. ${ }^{10}$

NMR spectra were obtained on either a Varian Associates Model Unity300 NMR spectrometer or a Varian Associates Model VXR-200. GCMS (EI Mode) analyses were performed on a Hewlett Packard 5971 Mass spectrometer. CIMS analyses were carried out on a Finnigan Incos-50 MS instrument. High resolution MS analyses of all new compounds were conducted at the University of California at Riverside.

\section{General procedure for preparation of bis-sulfides via reductive thiolation of carbonyl compounds}

To a well stirred solution of $10 \mathrm{mmol}$ dicarbonyl compound (or dithiol) and $20 \mathrm{mmol}$ thiol (or carbonyl compound) in $15-30 \mathrm{ml} \mathrm{CH}_{2} \mathrm{Cl}_{2}$ at $0^{\circ} \mathrm{C}$ was added dropwise $2 \mathrm{ml}$ of $\mathrm{BF}_{3}: \mathrm{H}_{2} \mathrm{O}$ (40 mmol). After 5-10 minutes, triethylsilane $(22 \mathrm{mmol})$ diluted in $10 \mathrm{ml} \mathrm{CH}_{2} \mathrm{Cl}_{2}$ was added dropwise. The reaction mixture was then stirred for 2 hours at room temperature, followed by quenching with ice water. The quenched mixture was extracted with $\mathrm{CH}_{2} \mathrm{Cl}_{2}(3 \times 25 \mathrm{ml})$. The combined organic extract was washed sequentially with aq. $10 \% \mathrm{KOH}$ solution and water, dried (over $\mathrm{CaCl}_{2}$ ) and evaporated in a rotary evaporator. The product was further purified either by distillation or recrystallization.

$\alpha, \alpha^{\prime}$-Bis(ethylthio)-p-xylene (4a). The reaction of terephthaldicarboxaldehyde with ethanethiol in the presence of $\mathrm{Et}_{3} \mathrm{SiH}$ and $\mathrm{BF}_{3}: \mathrm{H}_{2} \mathrm{O}$ gave $4 \mathbf{a}$ as a colorless liquid, which solidified at room temperature after four days; b.p. $135-137^{\circ} \mathrm{C} / 1 \mathrm{mmHg}$, lit. $^{2 \mathrm{c}}$ $110^{\circ} \mathrm{C} / 0.1 \mathrm{mmHg} ;{ }^{13} \mathrm{C} \mathrm{NMR}\left(\mathrm{CDCl}_{3}\right) \delta 137.2,128.8,35.5,25.2,14.3$; MS (EI mode) $\mathrm{m} / \mathrm{z}$ (relative intensity) $226\left(\mathrm{~m}^{+}, 76\right), 197$ (1), 165 (100), 136 (18), 135 (16), 104 (36), 91 (22), 78 (8).

$\alpha, \alpha^{\prime}$-Bis(n-propylthio)-p-xylene (4b). The reaction of terephthaldicarboxaldehyde with $n$-propanethiol in the presence of $\mathrm{Et}_{3} \mathrm{SiH}$ and $\mathrm{BF}_{3}: \mathrm{H}_{2} \mathrm{O}$ gave $\mathbf{4 b}$ as a colorless liquid; b.p. $130132^{\circ} \mathrm{C} / 1 \mathrm{~mm}$ 
Hg. ${ }^{13} \mathrm{C}$ NMR $\left(\mathrm{CDCl}_{3}\right) \delta 137.2,128.8,35.8,33.3,22.4,13.4$; MS (EI mode) $\mathrm{m} / \mathrm{z}$ (relative intensity) $254\left(\mathrm{~m}^{+}, 47\right), 211(0.4), 197(100), 137$ (13), 136 (11), 135 (13), 104 (36), 91 (19), 78 (7). HRMS calcd. 254.1163, found 254.1171.

$\alpha, \alpha^{\prime}$-Bis(i-propylthio)-p-xylene (4c). The reaction of terephthaldicarboxaldehyde with $i$-propanethiol in the presence of Et3 $\mathrm{SiH}$ and $\mathrm{BF}_{3}: \mathrm{H}_{2} \mathrm{O}$ gave $4 \mathrm{c}$ as colorless crystals. m.p. $54-55^{\circ} \mathrm{C}$ (from ethanol); ${ }^{13} \mathrm{C}$ NMR $\left(\mathrm{CDCl}_{3}\right) \delta 137.3,128.8,34.8,34.3,23.1$; MS (EI mode) $\mathrm{m} / \mathrm{z}$ (relative intensity) $254\left(\mathrm{~m}^{+}, 57,179\right.$ (100), 137 (33), 135 (17), 104 (27), 91 (22), 78 (5). HRMS calcd. 254.1163, found 254.1154 .

$\alpha, \alpha^{\prime}$--Bis(t-butylthio)-p-xylene (4d). The reaction of terephthaldicarboxaldehyde with 2-methyl-2-propanethiol in the presence of $\mathrm{Et}_{3} \mathrm{SiH}$ and $\mathrm{BF}_{3}: \mathrm{H}_{2} \mathrm{O}$ gave 4d as colorless crystals; m.p. 91$92^{\circ} \mathrm{C}$ (from benzene-pentane); lit. ${ }^{2 \mathrm{c}} 90^{\circ} \mathrm{C},{ }^{13} \mathrm{C}$ NMR $\left(\mathrm{CDCl}_{3}\right) \delta 137.0$, 129.0, 42.8, 33.1, 30.9; MS (EI mode) $\mathrm{m} / \mathrm{z}$ (relative intensity) 282 $\left(\mathrm{m}^{+}, 51\right), 226$ (16), 193 (29), 170 (55), 137 (100), 123 (5), 104 (24), 91 (20), 57 (40).

$\alpha, \alpha$--Bis(phenylthio)-p-xylene (4e). The reaction of terephthaldicarboxaldehyde with thiophenol in the presence of $\mathrm{Et}_{3} \mathrm{SiH}_{\mathrm{H}}$ and $\mathrm{BF}_{3}: \mathrm{H}_{2} \mathrm{O}$ gave $4 \mathbf{e}$ as a powder white solid; m.p. $145-146^{\circ} \mathrm{C}$ (from ethanol); lit. ${ }^{2 \mathrm{c}} 141-142^{\circ} \mathrm{C} ;{ }^{13} \mathrm{C}$ NMR $\left(\mathrm{CDCl}_{3}\right) \delta 136.4,136.2,129.9$, 128.8, 126.4, 38.8; MS (CI mode) $\mathrm{m} / \mathrm{z}$ (relative intensity) $322\left(\mathrm{~m}^{+}\right.$, 0.05), 213 (0.9), 123 (0.4), 111 (1.2), 97 (0.2), 85 (4.4), 71 (12.4), 57 (40), 43 (100).

$\alpha, \alpha$-Bis(ethylthio)-p-diethylbenzene (6). The reaction of 1,4diacetylbenzene with ethanethiol in the presence of $\mathrm{Et}_{3} \mathrm{SiH}$ and $\mathrm{BF}_{3}: \mathrm{H}_{2} \mathrm{O}$ gave 6 as a colorless liquid; b.p. $128-130^{\circ} \mathrm{C} / 1 \mathrm{mmHg} .{ }^{13} \mathrm{C}$ NMR $\left(\mathrm{CDCl}_{3}\right) \delta 142.7,127.2,43.3,25.1,22.4,14.4 ;$ MS (EI mode) $\mathrm{m} / \mathrm{z}$ (relative intensity) $254\left(\mathrm{~m}^{+}, 24\right), 193$ (100), 165 (2), 164 (4), 163 (4), 149 (3), 132 (80), 117 (29), 91 (11), 77 (6). HRMS calcd. 254.1163, found 254.1154 .

Equatorial-equatorial and equatorial-axial isomers of 1,4bis(ethylthio)cyclohexane (8a). The reaction of 1,4-cyclohexandione with ethanethiol in the presence of $\mathrm{Et}_{3} \mathrm{SiH}$ and $\mathrm{BF}_{3}: \mathrm{H}_{2} \mathrm{O}$ gave $\mathbf{8 a}$ as a colorless liquid; b.p. $90-93^{\circ} \mathrm{C} / 1 \mathrm{mmHg} .{ }^{13} \mathrm{C}$ NMR $\left(\mathrm{CDCl}_{3}\right) \delta 42.0,41.7$, 
33.4, 29.8, 24.3, 24.0, 14.92, 14.85; MS (EI mode) $\mathrm{m} / \mathrm{z}$ (relative intensity), first isomer, $204\left(\mathrm{~m}^{+}, 70\right), 175$ (5), 143 (25), 142 (64), 127 (9), 114 (28), 113 (57), 99 (8), 81 (100), 80 (27), 79 (51); second isomer $204\left(\mathrm{~m}^{+}, 50\right), 175(100), 147$ (4), 143 (3), 142 (1), 114 (6), 113 (67), 81 (69), 80 (19), 79 (51). HRMS calcd. 204.1006, found 204.1001.

Equatorial-equatorial and equatorial-axial isomers of 1,4-bis( $i$ propylthio)cyclohexane (8b). The reaction of 1,4-cyclohexandione with 2-propanethiol in the presence of $\mathrm{Et}_{3} \mathrm{SiH}$ and $\mathrm{BF}_{3}: \mathrm{H}_{2} \mathrm{O}$ gave $\mathbf{8 b}$ as colorless liquid; b.p. $88-92^{\circ} \mathrm{C} / 1 \mathrm{mmHg} .{ }^{13} \mathrm{C} \mathrm{NMR}\left(\mathrm{CDCl}_{3}\right) \delta 41.2,40.8$, $33.8,33.5,33.1,30.4,23.8$; MS (EI mode) $\mathrm{m} / \mathrm{z}$ (relative intensity), first isomer, $232(\mathrm{~m}+, 56), 189(24), 157(21), 156(36), 155$ (5), 146 (7), 114 (46), 113 (87), 99 (14), 81 (100), 80 (21), 79 (49); second isomer $232(\mathrm{~m}+, 22), 191$ (11), 198 (100), 147 (91), 113 (82), 81 (99), 80 (14), 79 (45); HRMS calcd. 232.1319, found 232.1314.

Two diastereomers of 1,3-bis(ethylthio)pentane (10a). The reaction of 1,3-pentandione with ethanethiol in the presence of $\mathrm{Et}_{3} \mathrm{SiH}$ and $\mathrm{BF}_{3}: \mathrm{H}_{2} \mathrm{O}$ gave 10a as colorless liquid; b.p. $79-82^{\circ} \mathrm{C} / 12 \mathrm{mmHg} .{ }^{13} \mathrm{C}$ NMR $\left(\mathrm{CDCl}_{3}\right) \delta 44.5,44.3,37.5,37.0,24.0,23.8,22.0,21.5,14.9$, 14.8; MS(Ei mode) $\mathrm{m} / \mathrm{z}$ (relative intensity), first isomer, $192\left(\mathrm{~m}^{+}, 33\right)$, 163 (100, 135 (15), 121 (35), 115 (7), 101 (97), 89 (64), 75 (12), 69 (37), $61(56), 59$ (39); second isomer $192(\mathrm{~m}+, 29), 163(87), 135(12)$, 121 (26), 115 (7), 101 (100), 89 (71), 75 (13), 69 (43), 61 (54), 59 (42). HRMC calcd. 192.1006 found 192.1013.

Two diastereomers of 1,3-bis(i-propylthio)pentane (10b.) The reaction of 1,3-pentandione with 2-propanethiol in the presence of $\mathrm{Et}_{3} \mathrm{SiH}$ and $\mathrm{BF}_{3}: \mathrm{H}_{2} \mathrm{O}$ gave $\mathbf{1 0 b}$ as colorless liquid; b.p. 83$85^{\circ} \mathrm{C} / 12 \mathrm{mmHg} .{ }^{13} \mathrm{C}$ NMR $\left(\mathrm{CDCl}_{3}\right) \delta 45.3,36.8,36.2,33.8,33.5,23.9$, 23.8, 22.7. 22.0 MS (EI mode) $\mathrm{m} / \mathrm{z}$ (relative intensity), first isomer, 220 $\left(\mathrm{m}^{+}, 4\right), 177$ (44), 135 (100), 103 (16), 101 (40), 93 (23), 75 (8), 69 (15), 61 (31), 59 (17); second isomer $220\left(\mathrm{~m}^{+}, 3\right), 177$ (47), 135 (100), 103 (19), 101 (45), 93 (19), 75 (8), 69 (16), 61 (34), 59 (17). HRMS calcd. 220.1319, found 220.1320.

1,4-Bis(i-propylthio)butane (12a). ${ }^{\text {2a }}$ The reaction of 1,4-butanedithiol with acetone in the presence of $\mathrm{Et} 3 \mathrm{SiH}$ and $\mathrm{BF} 3: \mathrm{H} 20$ gave 12a as a colorless liquid; b.p. $78-81{ }^{\circ} \mathrm{C} / 1 \mathrm{mmHg} ;{ }^{13} \mathrm{C} \mathrm{NMR}\left(\mathrm{CDCl}_{3}\right) \delta 34.7,30.0$, 
30.0, 23.4; MS (EI mode) $\mathrm{m} / \mathrm{z}$ (relative intensity) $206\left(\mathrm{~m}^{+}, 14\right), 163$ (60), 121 (100), 89 (22), 87 (35), 79 (6).

1,4-Bis(cyclohexylthio)butane $\quad(\mathbf{1 2 b}) .^{2 a}$ The reaction of $1,4-$ butanedithiol with cyclohexanone in the presence of $\mathrm{Et}_{3} \mathrm{SiH}$ and $\mathrm{BF}_{3}: \mathrm{H}_{2} \mathrm{O}$ gave 12b as viscous oil. Purification of 12b was carried out by low temperature recrystalization from EtOH. ${ }^{13} \mathrm{C}$ NMR $\left(\mathrm{CDCl}_{3}\right) \delta$ 43.4, 33.7, 29.6, 29.1, 26.0, 25.8. MS (CI mode) $\mathrm{m} / \mathrm{z}$ (relative intensity) $287\left(\mathrm{~m}^{+}+1,13\right), 286$ (9), 203 (40), 171 (100), 121 (8), 89 (14).

1,4-Bis(phenylthio)butane (12c). ${ }^{2 a}$ The reaction of 1,4-butanedithiol with benzaldehyde in the presence of $\mathrm{Et}_{3} \mathrm{SiH}$ and $\mathrm{BF}_{3}: \mathrm{H}_{2} \mathrm{O}$ gave 12c as colorless oil. Purification of 12c was carried out by low temperature recrystalization from EtOH. ${ }^{13} \mathrm{C} \mathrm{NMR}\left(\mathrm{CDCl}_{3}\right) \delta 138.4,128.7,128.4$, 126.9, 36.1, 30.7, 28.0. MS (CI mode) $\mathrm{m} / \mathrm{z}$ (relative intensity) 303 $\left(\mathrm{m}^{+}+1,7\right), 302$ (0.3), $211(36), 179$ (100), 119 (9), 91 (43).

1,5-Bis(n-propylthio)pentane $\quad(\mathbf{1 4 a}) .^{2 a}$ The reaction of $1,5-$ butanedithiol with propionaldehyde in the presence of $\mathrm{Et}_{3} \mathrm{SiH}$ and $\mathrm{BF}_{3}: \mathrm{H}_{2} \mathrm{O}$ gave 14a as colorless liquid; b.p. $88-90^{\circ} \mathrm{C} / 1 \mathrm{mmHg} ;{ }^{13} \mathrm{C} \mathrm{NMR}$ $\left(\mathrm{CDCl}_{3}\right) \delta 34.2,31.9,29.3,28.2,23.0,13.5$. MS (EI mode) $\mathrm{m} / \mathrm{z}$ (relative intensity) $220\left(\mathrm{~m}^{+}, 55\right), 177$ (53), 145 (35), 115 (25), 103 (28), 102 (71), 103 (69), 89 (100), 69 (59).

1,5-Bis(i-propylthio)pentane $(\mathbf{1 4 b}) .^{2 \mathrm{a}}$ The reaction of $1,5-$ butanedithiol with acetone in the presence of $\mathrm{Et}_{3} \mathrm{SiH}$ and $\mathrm{BF}_{3}: \mathrm{H}_{2} \mathrm{O}$ gave 14b as colorless liquid; b.p. $80-82^{\circ} \mathrm{C} / 1 \mathrm{mmHg} ;{ }^{13} \mathrm{C} \mathrm{NMR}\left(\mathrm{CDCl}_{3}\right) \delta$ $34.7,30.3,29.4,28.3,23.3$; MS (EI mode) $\mathrm{m} / \mathrm{z}$ (relative intensity) $220\left(\mathrm{~m}^{+}, 13\right), 177(81), 145(10), 135$ (85), 103 (45), 102 (29), 101 (100), 89 (49), 69 (68), 59 (38).

m-Bis(n-propylthio)benzene (16a). The reaction of 1,3-benzenedithiol with propionaldehyde in the presence of $\mathrm{Et}_{3} \mathrm{SiH}$ and $\mathrm{BF}_{3}: \mathrm{H}_{2} \mathrm{O}$ gave 16a as colorless liquid; b.p. $128130^{\circ} \mathrm{C} / 1 \mathrm{mmHg}$ lit $^{2 \mathrm{~b}} 112-113^{\circ} \mathrm{C} / 0.5 \mathrm{mmHg}$. ${ }^{13} \mathrm{C} \mathrm{NMR}\left(\mathrm{CDCl}_{3}\right) \delta 137.7,129.0,128.5,125.9,35.5,22.4,13.4$. MS (EI mode) $\mathrm{m} / \mathrm{z}$ (relative intensity) $226\left(\mathrm{~m}^{+}, 100\right), 197$ (3), 184 (64), 155 (23), 142 (85), 121 (8), 91 (31), 78 (17).

m-Bis(i-propylthio)benzene (16b). The reaction of 1,3-benzenedithiol with acetone in the presence of $\mathrm{Et}_{3} \mathrm{SiH}$ and $\mathrm{BF}_{3}: \mathrm{H}_{2} \mathrm{O}$ gave 16b as colorless liquid; b.p. $112-113^{\circ} \mathrm{C} / 1 \mathrm{mmHg}, \mathrm{lit}^{2 \mathrm{~b}} 102-103^{\circ} \mathrm{C} / 0.62 \mathrm{mmHg}$. ${ }^{13} \mathrm{C}$ NMR $\left(\mathrm{CDCl}_{3}\right) \delta 136.3,134.3,129.8,128.9,38.1,23.0$; MS (EI 
mode) $\mathrm{m} / \mathrm{z}$ (relative intensity) $226\left(\mathrm{~m}^{+}, 68\right), 211$ (2), 184 (26), 142 (100), 108 (12), 97 (9), 91 (2), 78 (9).

\section{Acknowledgements}

We thank Dr. Robert Aniszfeld for performing CI MS analysis. Support of our work by the Loker Hydrocarbon Research Institute is gratefully acknowledged.

\section{References}

1. Considered Synthetic Methods and Reactions. Part 180. For Part 179, see: Olah, G. A.; Ramaiah, P.; Prakash, G. K. S.; Gilardi, R. J. Org. Chem. 1993, 58, 763.

2. (a) Anklam, E. Synthesis, 1987, 841. (b) Kuliev, A.M.; Aliev, S.M. Azerb. Khim. Zh. 1968, 2, 82; Chem. Abstr. 1969, 70, 19718 g.

(c) Kader, A.T.; Stirling, J. M. J. Chem. Soc. 1962, 3425.

3. (a) Ikehira, H.; Tanimoto, S.; Oida, T. J. Chem. Soc. Perkin Trans. I, 1984, 1223. (b) Caserio, M.C.; Fisher, C. L.; Kim, J. K. J. Org. Chem. 1985, 50, 4390. (c) Tagaki, W. In Organic Chemistry of Sulfur." Oae, S., Ed.; Plenum Press: New York, 1977; Ch. 6.

4. Olah, G.A.; Wang, Q.; Trivedi, N.; Prakash, G. K. S. Synthesis 1992, 465.

5. Kikugawa, Y. Chem. Lett. 1981, 1157.

6. Degl'Innnocenti, A.; Capperucci, A. Sulfur Rep. 1998, 20, 279.

7. We are currently investigating the possibility of copolymerization of dithiols with dicarbonyl compounds.

8. Labiad, B.; Villemin, D. Synthesis 1989, 143.

9. Olah, G.A.; Wang, Q.; Li, X.Y.; Prakash, G.K.S. unpublished results.

10. (a) Larsen, J.W.; Chang, L.W. J. Org. Chem. 1979, 44, 1168. (b) Cheng, J.C.; Maioriello, J.; Larsen, J. W. Energy and Fuels 1989, 
3, 321 . 